\title{
Basic, Intermediate and Advanced Search: Group Data Sic
}

\author{
Pessoa Marcelo
}

Department of Linguistics and Communication, State University of Minas Gerais, Belo Horizonte, Brazil

Email address:

mpmarcelopessoa@yahoo.com.br

\section{To cite this article:}

Pessoa Marcelo. Basic, Intermediate and Advanced Search: Group Data Sic. Arabic Language, Literature \& Culture. Vol. 2, No. 4, 2017, pp. 75-79. doi: 10.11648/j.allc.20170204.11

Received: November 16, 2017; Accepted: January 26, 2018; Published: February 6, 2018

\begin{abstract}
This paper presents data about the research and production of the authors published by the CIS. The goal is to make transparent the moment this research group prioritized the development of competence in production and scientific disclosure in basic level, together with the average and advanced search.
\end{abstract}

Keywords: Scientific Dissemination, Research Group SIC, AKEDIA Journal

\section{Introduction}

SIC research group (society, culture and Images), born of change of name of the OCE Group (Organization, culture and State) to the current name - SIC, he began his research and knowledge production in UEMG, Fruity, Unit in the year 2011.

The premise of the research group OCE/SIC, then, was that this research group was a "nursery of research groups", that is, gusted new research groups to the unit, this academic Fruity, at the time, appointed himself "Frutal" Campus even if legally speaking this part of Campus, in 2011, still could not be granted and that in 2017, still can't.

Due to this condition, was a big turnover of researchers within the group, as well as the exaggerated the amount of record researchers enrolled as participants in the SIC. There were times when we had more than 40 (forty) members enrolled in the ranks of the SIC, besides students and technicians [9].

Excesses aside, the role of the SIC Group outside gestational fulfilled, since, in 2017, it is worth mentioning that relate in UEMG, Fruity, Unit 12 (twelve) research groups, and 07 (seven) in the area of law; 01 (one) in the area of sanitary engineering; 01 (one) in the area of the letters; 01 (one) in the area of Sociology; 01 (one) in the area of Social Communication; and, 01 (one) in the area of ecology.

However, only from the year 2013 is, in fact, the basic vocation of SIC and your leadership Group has been consolidated in the direction to meet the other demands of research and extension, which is not the first one to generate new research groups [1].

Pitching perspectives on the increased guidance, writing and scientific dissemination in basic research level is that the new academic-scientific North of SIC if defined [1].

From research and extension products generated within the research line "profiles of Urban Education", which is one of the two lines of research that underpin much of the scientific production of the SIC Group, the current setting of the SIC emerged [9].

Join in the consolidation of SIC Group since your birth the development of interdisciplinarity that the plurality of courses with which conversation on UEMG, incorporated in its publications curriculum components of matrices, Bachelor's degree in the Right, Bachelor's degree in Administration, Bachelor's degree in Geography, Bachelor's degree in Social Communication (specialization in journalism and in advertising), and Bachelor's degree in Information Systems [2].

It is worth saying that this current internal dynamics the group surfaced, too, due to the fact that in your Unit, Frutal UEMG, had already sensed that, to improve the quality of student freshman in undergraduate courses, it would be necessary to empower your audience better candidates before even the entrance exam, which began to offer local and regional society in the unit, a Cram Social Frutal what actually happened to happen in 2012, in character of extension project.

Thus, it was noticed that, over time, with the emergence of post-graduation courses Lato Sensu in Frutal Unit and with the Stricto Sensu Courses projects being proposed, a new demand of student empowerment should be triggered as soon as possible, so that If form stakeholders better qualified to 
develop Scientific Projects and, consequently, more apt to be offered to graduate programs to be created also in Frutal Unit, which could be achieved by giving to candidates initially a greater familiarity with writing and scientific publications and so on.

That's how the group brought to the public, SIC along their 06 (six) early years of existence, a set of at least 15 (fifteen) complete works and other actions, hereinafter outlined year after year, since your creation in 2011, updated until end of 2017, which inform, in addition to the publications, the creation of a startup company, the MPEducational, and a scientific journal with half-yearly Edition, named AKEDIA Scientific Journal - versions, negligence and other worlds.

These actions and publications, highlights the fact that, as for ISBNs and ISSNs, 05 (five) were issued by SIC and ISBNs that 07 (seven) were issued by other editorial sources. Also, it should be noted that only one ISSN was issued by SIC, there is no report of ISSN published by SIC from other publishing.

So, as the internationalization, which is a qualitative criterion for measuring scientific production, UEMG of SIC Group, one can point out that there was a publication in Germany in the year 2013, a publication in French in the year 2014, and an edition in English in the year 2014.

Also, it can be said that, in quantitative terms, the scientific production of the SIC Group so is presented in 15 (fifteen) publications:

2011

Year of creation OCE (Research Group Organization, culture and State), where, later in the same year, if renamed as SIC (society, culture and Images)

NURSERY GROUPS AND CONDUCTING POST DOC AT USP-SP

2012

PREVIATTELLI, Daniel; PESSOA, Marcelo; CORGOSINHO, Paulo. Invisible diversity - beyond what we can see. São Paulo: CNPQ / FAPESP, 2012, 28 p., $1^{\text {a }}$ Ed. in Portuguese, ISBN: 978-85-914769-3-0.

PESSOA, Marcelo; ROMAO-MURARI, A. P. F.; FRANCO, L. M. (Orgs.). In General Science multidisciplinary studies. Barbacena - MG: EdUEMG - The editor of the University of Minas Gerais, 2012, 112 p., ISBN 9788562578212.

2013

PESSOA, Marcelo (et. al.). Languages: science society \& systems in focus. Frutal, Marcelo Pessoa de Oliveira, 2013, 130 p., ISBN 978-85-909861-1-9.

PESSOA, Marcelo. The Chronicle a song by Chico Buarque. Curitiba: APPRIS, 2013, 271 p., ISBN 978-858192-107-5.

2014

PESSOA, Marcelo. The Chronicle Song of Caetano Veloso. Saarbrücken, Deutschland: NEA, 2014, 305 p., ISBN 978-363-961-605-7.

PESSOA, Marcelo; SILVA, M. B. C. (Org.); FRANCO, L. M. (Orgs.). The multiple Faces of education. Barbacena-
MG: EdUEMG, 2014, 199 p., ISBN 9788562578465.

PREVIATTELLI, Daniel; PESSOA, Marcelo; CORGOSINHO, Paulo. Invisible diversity - beyond what we can see. São Paulo: CNPQ / FAPESP, 2014, 28 p., $2^{\text {a }}$ Ed. em inglês, ISBN: 978-85-914769-1-6.

PREVIATTELLI, Daniel; PESSOA, Marcelo; CORGOSINHO, Paulo. Invisible diversity - beyond what we can see. São Paulo: CNPQ / FAPESP, 2014, 28 p., $3^{\text {a }}$ Ed. em francês, ISBN: 978-85-914769-2-3.

WRITE BOOK post DOC - publication scheduled for 2018

2015

PESSOA, Marcelo (Org.). Publications of the research group SIC - society, culture and Images. Frutal: Prospectiva, 2015, 148 p. (Vol. Administration course), ISBN 978-8567463-82-7.

PESSOA, Marcelo (Org.). Scientific Journal AKEDIA Versions, Negligence and other worlds. Frutal - MG, Marcelo Pessoa de Oliveira, V. I, 2015, 129 p., ISSN 24477656.

PROJECT KYOKAI -Initiation into Sports in Karate Mode - since then, participation in Pre-Olympic tournaments/Brazilian Championships/Competitions/03 implementation State Scholars and considerable community interest in the practice of sport in focus.

2016

CONSTITUTION of MPEDUCATIONAL and

CREATING the SITE to disseminate much of the scientific production of SIC:

http://mpmarcelopessoa.wixsite.com/akediaonline

PESSOA, Marcelo (Org.). Scientific Journal AKEDIA Versions, Negligence and other worlds. Frutal - MG, Marcelo Pessoa de Oliveira, V. II, 2016, 191 p., ISSN 24477656.

PESSOA, Marcelo (Org.). Scientific Journal AKEDIA Versions, Negligence and other worlds. Frutal - MG, Marcelo Pessoa de Oliveira, V. III, 2016, 105 p., ISSN 24477656.

2017

PESSOA, Marcelo. Digital Novel. Frutal - MG: Marcelo Pessoa de Oliveira, 2017, 24 p., ISBN 978-85-909861-4-0.

PESSOA, Marcelo. Divulgação científica universitária. Frutal - MG: Marcelo Pessoa de Oliveira, 2017, 113 p., ISBN - 978-85-909861-3-3.

PESSOA, Marcelo. University Science. Frutal - MG: Marcelo Pessoa de Oliveira, 2017, 113 p., ISBN - 978-85909861-2-6.

Important information being put in evidence with respect to these 15 (fifteen) publications, relates also to the caliber of the institutions involved in the publications of the SIC -21 (twenty one) - elements that when they give evidence of the meeting how each one can contribute heavily for local and regional development within the context in which they are installed, whereas the capillarity of the institutions in itself promotes higher dispersion of publications through the headquarters of its authors, which are allocated by virtually every corner of the country, covering almost all geographic 
regions of Brazil and already reaching some countries in South America and Europe:

Elementary schools and high schools of the State - MG

FAF - Faculty of Frutal - MG

FAPP - Faculty of public policies Tancredo Neves -

$\mathrm{UEMG}-\mathrm{BH}-\mathrm{MG}$

IFG - Federal Institute of Goiás - GO

IFSP - Federal Institute of de Barretos - SP

IFMG - Federal Institute of Minas Gerais - BH

IFSP - Federal Institute of Boituva - SP

IHE - Delft Institute for Water Education - Holanda HOL

IMESB -Municipal Institute of higher education in

Bebedouro - SP

UAL - Open University of Lisbon - PORT

UEMG - University of the State of Minas Gerais - Frutal

$-\mathrm{MG}$

UFGO - Federal Institute of Goiânia - GO

UFSCAR - Federal University of São Carlos - SP

UFSM - Federal University of Santa Maria - RS

UFU - Federal University of Uberlândia - MG

UNESP -Estadual Paulista University - Bauru - SP, e

Advisor FAPESP

UPLA - Universidad de Playa Ancha - Chile - CHI

USP - University of São Paulo - SP

UNIESP - MG

UFMT - Federal University of Mato Grosso - Alto

Araguaia - MT

U. PORTO - University of Porto - Lisbon - PORT

When the public or private nature of educational institutions origin of our authors, as well as regarding the regional boundaries and the glimpse of internationalization of research through the location of establishments that publish in the SIC, are in number of 17 (Seventeen) and that are so willing:

Southern Region........................................................... 01

Southeast Region.......................................................... 13

Midwest Region..........................................................03

Northern Region............................................................. 00

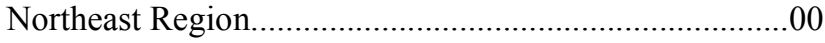

Educational institutions:

Municipals.................................................................. 01

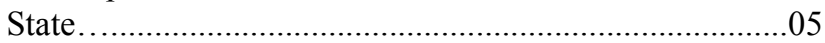

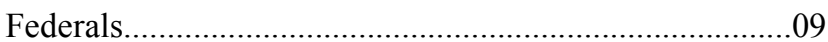

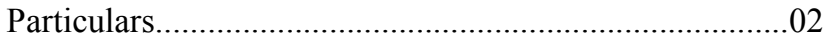

In International Territory, are 04 (four) Institutions with which the SIC, and are thus distributed dialogues:

Other countries in South America (Chile).....

Europe (Germany, Netherlands, Portugal).

\section{Theoretical Background: The Methodology}

On the initiative of the SIC group leadership, Prof. Dr. Marcelo Pessoa, openness to the development of a practice of student training that made the construction of knowledge around the scientific language and your consequent dissemination in scientific publications (papers, abstracts, books, book chapters etc.) [6]. So, since the first period of undergraduate courses in the Frutal UEMG undergraduate student or even community members who have an interest in such practices, they could approach the SIC Group or your leadership and receive guidance from the Teacher responsible reliable [3].

So, slowly, with the essential principles of scientific language, began to produce and publish academic texts under guidance and coauthor ship with Prof. Dr. Marcelo Pessoa or of their respective mentors when it came to [6].

As to the authorship of the texts, that is to say that almost all undergraduates Fruity unit were published as co-authors by the Faculty leader of the SIC in the works more or less complex, depending on the nature of each, since they were under the care of Prof. Dr. didactic Marcelo Pessoa and, in this condition, in addition to the credits of their respective publications, have been able to access, understand and exercise a learning and practice of writing which derived from the classroom application of methodology PBL (Problem Based Learning) [4].

During the lessons of Research in business, in the year 2015, the PBL was applied in a class of the second morning and night period of the course of administration, UEMG University of State of Minas Gerais, Frutal, which promoted intense involvement students with the proposal and a significant elevation in the academic performance of students.

This same approach was later (in the year 2016) employed in another class of the same course in the same academic Unit Administration and, in 2017, was extended to Degree courses in geography, to advertising, to the course of journalism, involving, This time, students of 1 (first), 5 (fifth) and 8 (Eighth), all periods of UEMG, Frutal.

The PBL methodology, it should be recalled, develops from the articulation of three main actors: the Guardian (the teacher), the Coordinator (role assumed by a pupil, leader or leader of GT - working group), and the rapporteur (some students team member, GT), which passes the draft, to record the results of the discussions and the advances and setbacks obtained vis-à-vis the objectives previously outlined.

The PBL, or literally referenced "Problem-based Learning", is historically a teaching approach that arose in northern countries, especially Canada, between the decades of 1960 and 1970. Initially focused on academic practices of the faculties of Medicine, the PBL to win the world due to your aura of pedagogical innovation - structured topics discussed within GTs (Workgroups), and contemporary, developed in brain Storm, and student self-management of the contents [4].

\section{The Results}

This method reproduces primarily from a few steps well delimited by professor: a) clarification of difficult terms - 
which usually happens during the first lecture of a discipline; b) definition of the problems to be understood and explainedfrom here is that were created the GTs and the research themes were delimited; c) analysis of the problems-in this moment is that the GTs began to select the ideal methodology for the development of their research [7]; d) give the possible explanations, according to previous knowledge - "brain storming" -in this step the GTs were the practice of research (that is, those who predicted bibliographical revision, left for the removal of the material, the who predicted field research, left for data collection, interviews etc.); e) Summarize-at this stage the role of the Tutor was decisive in helping the GTs to select the bibliographic material, to draw up summaries and apply properly the research methods; f) Formulate learning objectives - this is an introductory phase of all the work of the semester, which begins with the reading and discussion of the menu of the discipline, but that permeates the whole process of knowledge construction; g) Individual study based on the step described in the letter "e" - this is where the GTs promote densification theoretical or methodological refinement of their research; h) Reporting to the group - in these times the GTs are returning to the classroom, in a collective meeting feedback, transmitting to others their research experiences GTs, their successes and frustrations, causing all GTs apprehend, from these reports, lessons that serve them, taking advantage of or rejecting pipelines; I) discuss - when the results appear, even if treated, but that approach or not the respective formats proposed by the Tutor (in our case, we predicted Abstracts, Expanded Abstracts e Scientific Articles). In the PBL method, as it turns out, favoring the improvement in the pupil of your ability to work in groups. At the same time, this approach removes the student from the traditional role of fellow patient, making the agent responsible for learning and the construction of knowledge, which occurs simultaneously by means of studies directed by the Tutor and has developed an online self-directed by GTs. That is, the knowledge of a world shared by all in the classroom, and especially the knowledge of a student's world are valued, which collaborates in order to deconstruct in student's mind the impression that students can't work in cooperation or to continue dependent on the "reins" teacher's teaching [5]. From these assumptions, then, researcher, Editor overlapped, teaching and group leader, is to assume the role of Guardian of PBL and the works of the SIC have been made public.

\section{Discussion: Some Parameters Quali/Quantitative and Sic Production}

The objectives proposed to the Group of research since your creation in 2011 and which have been extended until this 2017 year have never been modest. On the other hand, the proposal to generate interest in the local academic community through the creation of research groups. On the other hand, outline ways for the delivery of scientific production of middle and advanced basic research, which until recently was dammed by the wall of inertia of some scholars who have seen the publication of undergraduatelevel students a chance the omission of the managers, academics who never even looked at these production items or when the saw, gave (and still give them as scientifically irrelevant), the scarcity of vehicles created for this purpose, or even without a perspective adequate flow to your model [7].

The second demand arose in the SIC (to break the levees of omission, of scarcity, the inertia that prevented the fluidity of some productions), therefore, found refuge from the development inside and outside the classroom guidelines of academic papers developed for my students and some fellow researchers more daring [5].

Thus, the guidelines carried out without the supply of bags or completion Work level of undergraduate course or those motivated by the conduct of this or that discipline given make up the amount of 228 (two hundred and twenty eight) students, this number is per se plication name limited which operated until then.

For your time, the guidelines implemented with graduatelevel scholarship in scientific initiation and University extension, prefix a total of 06 (six) notes.

The guidelines articulated in graduate-level courses feature a volume of 11 (eleven) menus.

Perhaps for this reason, is that the numbers resulting from publication presented below impress, wants to be seen as a function of the total volume of 119 different titles of texts published, distributed as follows, according to their respective scientific levels:

Organization of books published.....................................05

Books co-authored.........................................................04

Copyright Books Published...........................................03

Chapters of books published.........................................60

Full Scientific Articles...................................................21

Presentation of published Works......................................09

Text Production Free........................................................09

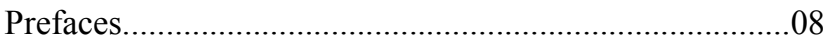

Whether seen these texts as itemized above, from the point of view of how that made it possible to its 299 (two hundred and ninety and nine) authors a total of 495 (four hundred and ninety and five) entries for the curriculum LATTES. In that respect, it is noteworthy that the 495 items of academic production due to 184 (one hundred and eight and four) curricular Teaching production inputs, 301 (three hundred and one) student production inserts - undergraduate and graduate program, and 10 (ten) production of Technical items and other graduates.

The hierarchical description of 299 - academic authors who published in SIC Group (45 - forty five - teachers; 242 - two hundred and forty and two - undergraduate and graduate students; and 12 - twelve - technicians or graduates UEMG), are, according to the following status:

Undergraduates........................................................228

Graduates/Technicians.........................................06 + 06

Graduates.................................................................... 14 


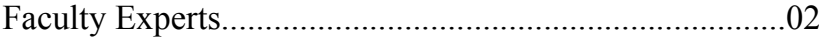

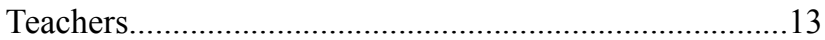

Teachers Doctors.......................................................24

Teachers Post-Doctors.......................................................

Free Teachers-Teachers...................................................01

\section{Conclusions}

This scientific production represents a strong academic production, whether considered from the point of view of total high students to degree of authors (242), which had, for the first time, an opportunity to have their names appearing as writers of a text academic.

The knowledge generated by the SIC, if glimpsed from the perspective of the different texts published volume (119one hundred nineteen) also suggests academic force on completion of the mission that fit. Also, from the point of view of the amount of authors who are teachers (45 - forty five), is worthy of note that they all have enriched their Curriculum LATTES in some way with their publications or offering your professional prestige writing advice Editorials of the works broadcast by SIC, which is academically important.

However, perhaps the most important factor to be weighed in here at the end of writing, to the point that there are few or almost no initiative in academia that focuses on the production and dissemination of products generated by basic research, especially that which massively involved the community students. And that, above all, if you do this by calling (as is the case of the SIC), i.e., in continuous and dedicated character, and not on the occasion of the completion of this or that academic-scientific event that will organize.

Between 2011 and 2017, the SIC provided the 228 (two hundred and twenty eight) undergraduate students and 14 (fourteen) graduates, an opportunity to generate 311 publications for registration in their related Curriculum LATTES. Similarly, teachers who published in SIC, for your time, produced a volume of knowledge that generated 184 (one hundred and eighty four) production items that compose their professional portfolios.

In short, it is worth saying that to gestate in your bulge new research groups, to the point where today there 12 (twelve) research groups in the unit, the SIC had already Fruity fulfilled your dot matrix paper. However, this research group leadership is aware that, in developing this work of production and scientific disclosure by the academic community by publishing works that, by the massive involvement of undergraduates will not be able to count on the support of seal Qualis/CAPES in his works.
However, when we do that, we also have in mind not only the acquisition of prestige and support of institutions such as CAPES and other research funding agencies, even though we know a priori that such seal shall be given us not. But, then, what we want with it? Maybe, at last, in the first instance, our desire is to contribute so modest to improve human and technical training of our students this and only this. I know I'm not alone in this task, since other 45 (forty five) Teachers, technicians and Graduates 0606 also accepted the challenge to give your contribution in this purpose.

And finally, I leave here my thanks not least special, the authors Álvaro de Campos (1890-1935), Hans Christian Andersen (1805-1875), José Régio (1901-1969), Juan Ramon Rodriguez Sosa (? - ?), Maurício Nascimento (? - ?), Vincent Van Gogh (1853-1890) that, to make their works in the public domain on the internet, allowed some of our book covers, magazines, and legends would be brighter by using their lights.

\section{References}

[1] DUARTE, Jorge \& BARROS, Antonio. Métodos e Técnicas de Pesquisa em Comunicação. São Paulo: Atlas, 2011.

[2] CLAVAL, Paul. Epistemologia da Geografia. Florianópolis: UFSC, 2011.

[3] LAKATOS, Eva Maria; MARCONI, Marina de Andrade. Fundamentos de Metodologia Científica. São Paulo: Atlas, 1993.

[4] OLIVEIRA, Silvio Luiz de. Tratado de Metodologia Científica: projetos de pesquisas. TGI, TCC, monografias, dissertações e teses. $2^{\mathrm{a}}$ ed. São Paulo: Pioneira, 2000.

[5] MEDEIROS, João Bosco. Redação Científica - a prática de Fichamentos, Resumos, Resenhas. Atlas: SP, 2008.

[6] DUCROT, Oswald \& TODOROV, Tzvetan. Dicionário Enciclopédico das Ciências da Linguagem. São Paulo: Perspectiva, 2007.

[7] CHARAUDEAU, Patrick \& MAINGUENEAU, Dominique. Dicionário de Análise do Discurso. São Paulo: Contexto, 2008.

[8] REZENDE, Antônio Martinez de. Latina Essentia preparação ao latim. Belo Horizonte: EdUFMG, 2003.

[9] SASAKI, Chikara. Introdução à Teoria da Ciência. São Paulo: EdUSP, 2010.

[10] KUHN, Thomas. A Estrutura das Revoluções Científicas. São Paulo: Perspectiva, 2003. 